\title{
Genome wide expression profiling identifies genes associated with colorectal liver metastasis
}

\author{
H.-M. LIN ${ }^{1}$, A. CHATTERJEE ${ }^{1}$, Y.-H. LIN ${ }^{1}$, A. ANJOMSHOAA ${ }^{1}$, \\ R. FUKUZAWA ${ }^{1}$, J.L. McCALL ${ }^{2}$ and A.E. REEVE ${ }^{1}$ \\ ${ }^{1}$ Cancer Genetics Laboratory, Department of Biochemistry, Otago School of Medical Sciences, University of Otago, \\ P.O. Box 56, Dunedin; ${ }^{2}$ Department of Surgery, University of Auckland, Auckland, New Zealand
}

Received January 31, 2007; Accepted March 19, 2007

\begin{abstract}
Tumour cells have to undergo gene expression changes in order to metastasise and adapt to a new site. We investigated these changes in liver metastases of colorectal cancer by using genome-wide microarray analysis to profile the expression of 48 primary tumours and 28 liver metastases. Statistical analysis of these expression profiles using the significance analysis of microarrays (SAM) method identified 778 genes differentially expressed between primary tumours and metastases. Gene ontology analysis revealed that genes associated with tissue remodelling and immune response were upregulated in metastases relative to primary tumours, whereas genes associated with proliferation and oxidative phosphorylation were downregulated. Quantitative real-time PCR confirmed the differential expression of selected genes, osteopontin, versican, ADAM17, CKS2, PRDX1, CXCR4, CXCL12, and LCN2. The upregulation of genes associated with tissue remodelling and immune response are likely to be involved in metastatic invasion and colonisation of the new site because these genes can promote tumour progression. However, downregulation of genes associated with proliferation suggests that proliferation in metastases was reduced relative to primary tumours.
\end{abstract}

\section{Introduction}

Metastasis is the major cause of death amongst cancer patients. Approximately $50 \%$ of colorectal cancer patients have metastases in the liver, but only $10-20 \%$ of these patients can undergo surgical resection. The 5-year survival rate following surgical resection is only $30-40 \%$ (1).

Correspondence to: Professor Anthony E. Reeve, Cancer Genetics Laboratory, Department of Biochemistry, Otago School of Medical Sciences, University of Otago, P.O. Box 56, Dunedin, New Zealand

E-mail: anthony.reeve@stonebow.otago.ac.nz

Key words: colorectal cancer, metastasis, microarray, gene expression
The molecular events enabling the metastatic process and preferential spread to the liver are still not well-understood for colorectal cancer. Colorectal tumour cells have to undergo changes in gene expression through genetic mutation or in response to new extracellular signals to disseminate from the primary site and grow in the liver. These gene expression changes have been investigated by using DNA microarrays to profile colorectal tumours (2-6). However, only two microarray studies have compared the gene expression profile of colorectal primary tumours with that of liver metastases $(7,8)$.

We used DNA microarrays of 30,000 genes to profile the gene expression of 48 primary colorectal tumours and 28 liver metastases. Our aim was to elucidate the gene expression changes in colorectal tumour cells after metastasis to the liver in order to determine how the tumour cells adapt to the liver environment. We identified genes that are differentially expressed between primary tumours and metastases through statistical analysis of the microarray expression profiles. Gene ontology analysis of these genes revealed biological functions that relate to the adaptation of metastases to the new site and the effect of the new host organ on the metastases. Quantitative real-time PCR was carried out to confirm the differential expression of selected genes.

\section{Materials and methods}

Tissue samples. Forty-eight primary colorectal tumours, 10 non-malignant colon tissues, 28 liver metastases and 10 nonmalignant liver tissues were obtained with appropriate ethical approval from the surgery departments of public hospitals in Dunedin and Auckland, New Zealand. All tissue samples were snap-frozen following excision and stored at $-80^{\circ} \mathrm{C}$. Formalin-fixed paraffin-embedded primary colorectal tumours and liver metastases were obtained from the same sources.

Microarrays and reference RNA. Microarrays and reference RNA were prepared by Pacific Edge Biotechnology Limited, New Zealand. Microarray slides were epoxy-coated and printed with the MWG Human 30K oligo set (MWG Biotech). Reference RNA was RNA pooled from 17 cell lines of various cancers.

RNA extraction. RNA was extracted from homogenised tissue samples using TRI-reagent (Molecular Research Center), and 
Table I. Gene ontologies identified by EASE for genes upregulated in liver metastases relative to primary tumours.

\begin{tabular}{|c|c|c|c|c|c|}
\hline Category & $\begin{array}{l}\text { Biological } \\
\text { function }\end{array}$ & $\begin{array}{l}\text { Total } \\
\text { genes }\end{array}$ & $\begin{array}{l}\text { Ontology } \\
\text { level }\end{array}$ & $\begin{array}{l}\text { Ontologies upregulated } \\
\text { in liver metastases }\end{array}$ & $\begin{array}{l}\text { EASE } \\
\text { score }\end{array}$ \\
\hline \multirow[t]{7}{*}{ Biological process } & Immune & 24 & 2 & Response to stress & 0.000869 \\
\hline & response & & 3 & Response to wounding & 0.00273 \\
\hline & & & 3 & Response to pest/pathogen/parasite & 0.000224 \\
\hline & & & 3 & Immune response & 0.000415 \\
\hline & & & 4 & Inflammatory response & 0.00347 \\
\hline & Tissue & 22 & 2 & Cell communication & 0.00128 \\
\hline & remodelling & & 3 & Cell adhesion & 0.00187 \\
\hline Cellular component & $\begin{array}{l}\text { Tissue } \\
\text { remodelling }\end{array}$ & 22 & 1 & Extracellular matrix & 0.000159 \\
\hline \multirow[t]{3}{*}{ Molecular function } & Tissue & 22 & 2 & Receptor activity & 0.0019 \\
\hline & remodelling & & 2 & Carbohydrate binding & 0.00419 \\
\hline & & & 2 & Extracellular matrix structural constituent & 0.0078 \\
\hline
\end{tabular}

purified with Qiagen RNeasy mini kit (Qiagen Sciences). Prior to RNA extraction of liver metastases, $8-\mu \mathrm{m}$ sections adjacent to the area used for RNA extraction were stained with hematoxylin and eosin for microscopic examination to check the presence of liver tissue.

Amino-allyl cDNA labelling and microarray hybridisation. Amino-allyl cDNA labelling protocol was based on the DeRisi Lab protocol (http://derisilab.ucsf.edu). Reverse transcription of $10 \mu \mathrm{g}$ total RNA of tumour samples or reference RNA was performed using Supercript II RNase $\mathrm{H}^{-}$Reverse transcriptase kit (Invitrogen), with Poly-dT VN (Proligo) primer, and a $50 \mathrm{X}$ mixture of amino-allyl conjugated dUTP (Sigma Aldrich) and dNTP (Amersham Biosciences). AminoallylcDNA was conjugated with $\mathrm{Cy} 5$ or $\mathrm{Cy} 3$ monoreactive dye packs (Amersham Pharmacia Biotech). Microarray slides blocked with serum albumin were hybridised with the mixture of labelled-cDNA and Ambion SlideHyb\#1 for $18 \mathrm{~h}$ at $42^{\circ} \mathrm{C}$. Duplicate hybridisations were performed for 17 primary tumours, all liver metastases and all normal liver samples.

Scanning and data normalisation. Microarrays were scanned using a GenePix 4000B microarray scanner (Axon Instruments) and GenePix Pro 4.1 software (Axon Instruments). Intensities were normalised using SNOMAD methodology (9) modified by R. Schaffer and F. Pichler (unpublished data).

Data filtering and clustering. Normalised intensity values of all microarrays were collated and filtered using BRB-Array tools version 3.2 (developed by Dr Richard Simon and Amy Peng Lam, Biometric Research Branch, National Cancer Institute). Unsupervised hierarchical clustering of the filtered data was also performed with the same software, using centered correlation and average linkage for the distance method.
Identification of differentially expressed genes. Significance analysis of microarrays (SAM) implementation in TIGR multi-experiment viewer $(\mathrm{MeV})$ version 3.0 (The Institute for Genomic Research) was used to identify genes with significant differential expression between primary tumours and liver metastases. Two SAM comparisons were carried out: liver metastases versus 'primary tumours group 1', liver metastases versus 'primary tumours group 2'. Each group of primary tumours consisted of 24 samples profiled on arrays of a print run that differs from the other group of primary tumours. Parameters used in both SAM comparisons were: two-class unpaired, 1000 permutations, 'Tusher et al method' for selecting S0, K-nearest neighbours imputer (10 neighbours) for replacing missing values. The delta value was adjusted such that the median number of false significant genes was zero. A minimum fold change of 1.5-fold was selected as the threshold for genes to be differentially expressed between metastases and primary tumours. Differentially expressed genes that did not appear in both SAM comparisons (liver metastases versus 'primary tumour group 1'; liver metastases versus 'primary tumour group 2') were excluded since these genes may be false positives caused by print run differences. Genes highly expressed in normal liver were also excluded (explained in the next section). The remaining differentially expressed genes were annotated using the MWG clone set annotations from Resourcerer (http://compbio.dfci.harvard. edu/tgi/cgi-bin/magic/r1.pl).

Identification of genes highly expressed in normal liver. Microscopic examination estimated that liver metastases contained $20 \%$ liver tissue at most, thus genes with high expression in the contaminating liver tissue could appear as false positives amongst the genes upregulated in metastases relative to primary tumours. These potential false positives were identified as those upregulated by at least 7.5-fold in normal liver relative 


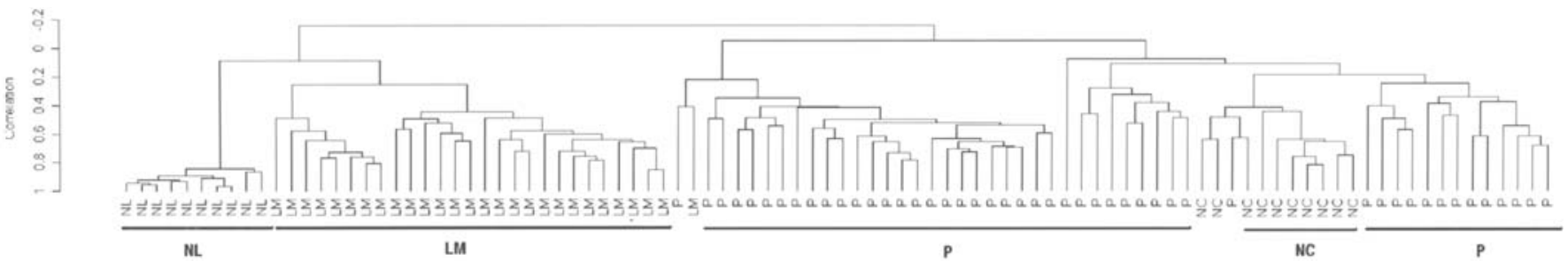

Figure 1. Unsupervised hierarchical clustering of tumour samples and normal tissues using the microarray expression profile of 11,238 genes. Distance method is centered correlation with average linkage. NL, normal liver; LM, liver metastasis; P, primary colon cancer; NC, normal colon.

Table II. Gene ontologies identified by EASE for genes downregulated in liver metastases relative to primary tumours.

\begin{tabular}{|c|c|c|c|c|c|}
\hline Category & $\begin{array}{l}\text { Biological } \\
\text { function }\end{array}$ & $\begin{array}{l}\text { Total } \\
\text { genes }\end{array}$ & $\begin{array}{l}\text { Ontology } \\
\text { level }\end{array}$ & $\begin{array}{l}\text { Ontologies downregulated } \\
\text { in liver metastases }\end{array}$ & $\begin{array}{l}\text { EASE } \\
\text { score }\end{array}$ \\
\hline \multirow[t]{8}{*}{ Biological process } & Chromosome & 13 & 5 & DNA metabolism & 0.00953 \\
\hline & organisation & & 6 & DNA packaging & 0.00576 \\
\hline & & & 8 & Chromatin assembly/disassembly & 0.00886 \\
\hline & & & 10 & Nucleosome assembly & 0.00263 \\
\hline & $\begin{array}{l}\text { Oxidative } \\
\text { phosphorylation }\end{array}$ & 21 & 6 & $\begin{array}{l}\text { ATP synthesis coupled } \\
\text { electron transport }\end{array}$ & 0.00076 \\
\hline & Cell & 25 & 3 & Cell proliferation & 0.00533 \\
\hline & proliferation & & 4 & Mitotic cell cycle & 0.00549 \\
\hline & & & 4 & $\begin{array}{l}\text { Regulation of progression } \\
\text { through cell cycle }\end{array}$ & 0.00688 \\
\hline \multirow[t]{4}{*}{ Cellular component } & $\begin{array}{l}\text { Protein } \\
\text { catabolism }\end{array}$ & 5 & 2 & $\begin{array}{l}\text { Proteasome core complex } \\
\text { (sensu Eukaryota) }\end{array}$ & 0.000696 \\
\hline & $\begin{array}{l}\text { Oxidative } \\
\text { phosphorylation }\end{array}$ & 21 & 4 & Mitochondrion & $2.41 \times 10^{-5}$ \\
\hline & Chromosome & 13 & 4 & Chromatin & $2.48 \times 10^{-7}$ \\
\hline & organisation & & 5 & Nucleosome & 0.000835 \\
\hline \multirow[t]{3}{*}{ Molecular function } & Oxidative & 21 & 3 & NADH dehydrogenase activity & 0.00309 \\
\hline & phosphorylation & & 3 & Cation transporter activity & 0.000287 \\
\hline & & & 5 & Hydrogen ion transporter activity & $1.86 \times 10^{-5}$ \\
\hline
\end{tabular}

to normal colon according to SAM analysis of the expression profiles of normal liver and normal colon $(20 \%$ of 7.5 -fold $=$ 1.5 -fold false positive, where 1.5 -fold is the minimum fold change chosen for genes differentially expressed between metastases and primary tumours).

Identification of significant gene ontologies. Stastistically significant gene ontologies among the differentially expressed genes were identified using the web-based version of expression analysis systematic explorer (EASE; http://david. abcc.ncifcrf.gov/). Genes were submitted to the software application in the form of Entrez Gene IDs.

Quantitative real-time PCR ( $Q P C R)$. Total RNA (2 $\mu \mathrm{g})$ was reverse transcribed using Supercript II RNase $\mathrm{H}^{-}$reverse transcriptase kit (Invitrogen) and oligo dT primer (Invitrogen). QPCR was performed on an ABI Prism 7900HT sequence detection system (Applied Biosystems) using Taqman gene expression assays (Applied Biosystems). The exception was CD44v10, which was analysed using in-house designed primers and FAM-TAMRA probe (Proligo). Relative fold changes were calculated using the $2^{-\triangle \triangle C T}$ method (10) with topoisomerase $3 \mathrm{~A}$ as the internal control. Reference RNA was used as the calibrator to enable comparison between different tissue types.

\section{Results}

Significance analysis of gene expression profiles. The gene expression of colorectal primary tumours, liver metastases, 
A
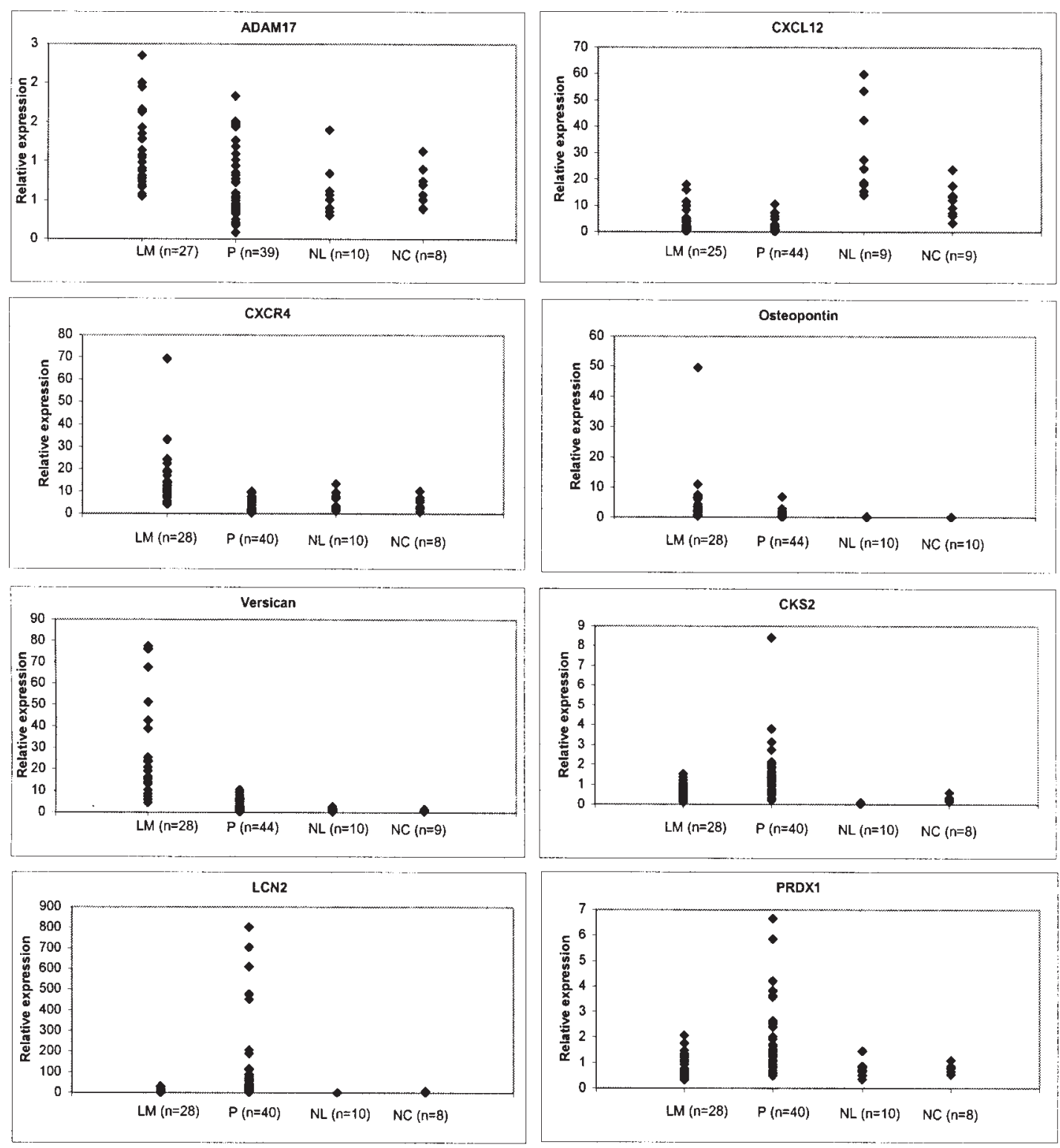

Figure 2. Scatterplots of QPCR-measured gene expression. (A) Expression of genes confirmed to be significantly different between liver metastases and primary tumours.

normal colon and normal liver samples were profiled using 30,000 oligonucleotide microarrays. Data filtering reduced the number of genes to 11,220 for significance analysis. Unsupervised hierarchical clustering of the tumours and normal tissues using these 11,220 genes clustered the samples into their respective groups, with only a few samples falling outside their groups (Fig. 1).

SAM analysis identified 1,837 genes showing statistically significant differential expression between the primary tumours and liver metastases. From these 1,837 genes, 31 were likely to be expressed by liver tissue, which included albumin and alcohol dehydrogenase. These 31 liver genes were thus excluded. Only 778 of the remaining 1,806 genes could be annotated with a GenBank number and had a fold difference of at least 1.5 between the primary tumours and liver metastases. These 778 genes consisted of 341 genes upregulated and 437 genes downregulated in liver metastases relative to the primary tumours.

Genes associated with immune response and tissue remodelling are upregulated in liver metastases. Gene ontology analysis identified immune response and tissue remodelling as statistically significant biological functions among the genes upregulated in liver metastases relative to primary tumours (Table I).

Genes associated with immune response include genes expressed by innate and adaptive immune cells, indicating the presence of both types of immune cells in the tumour stroma. Examples of genes expressed by innate immune cells are the proteoglycan 3 PRG3 and natural killer cell receptor NCR3. Genes expressed by adaptive immune cells include the T-cell derived cytokine interleukin $17 \mathrm{C}$ and the 
B
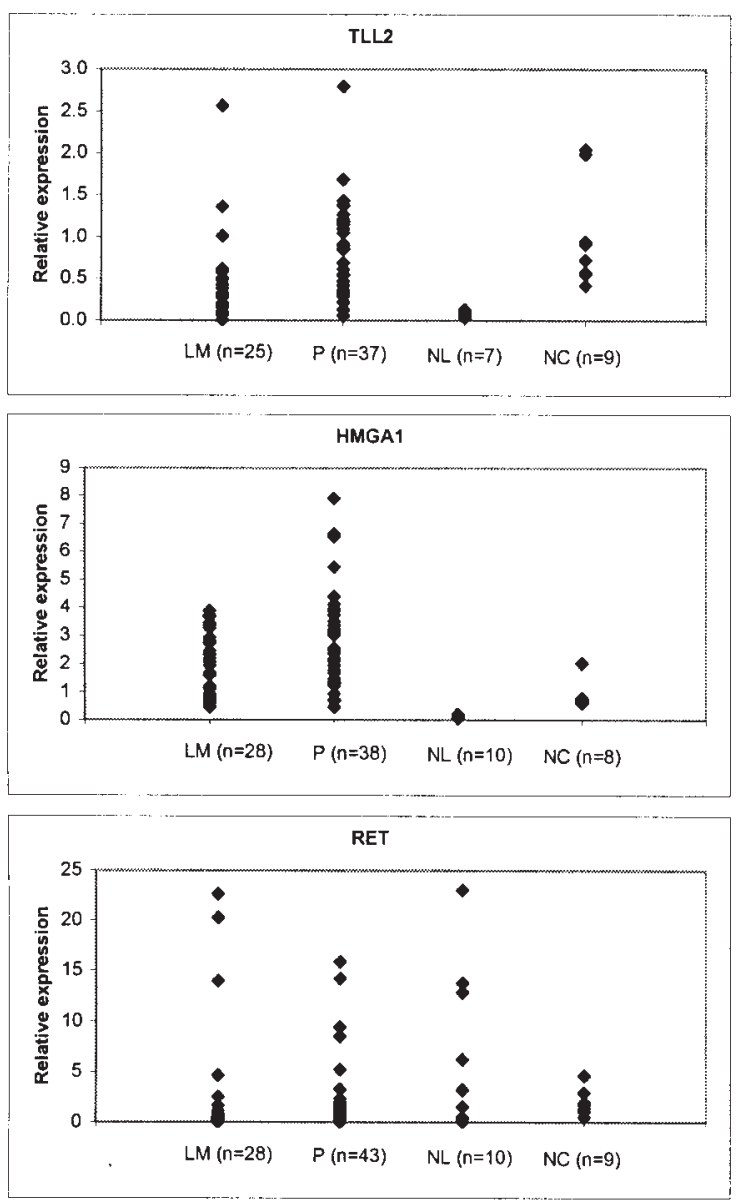
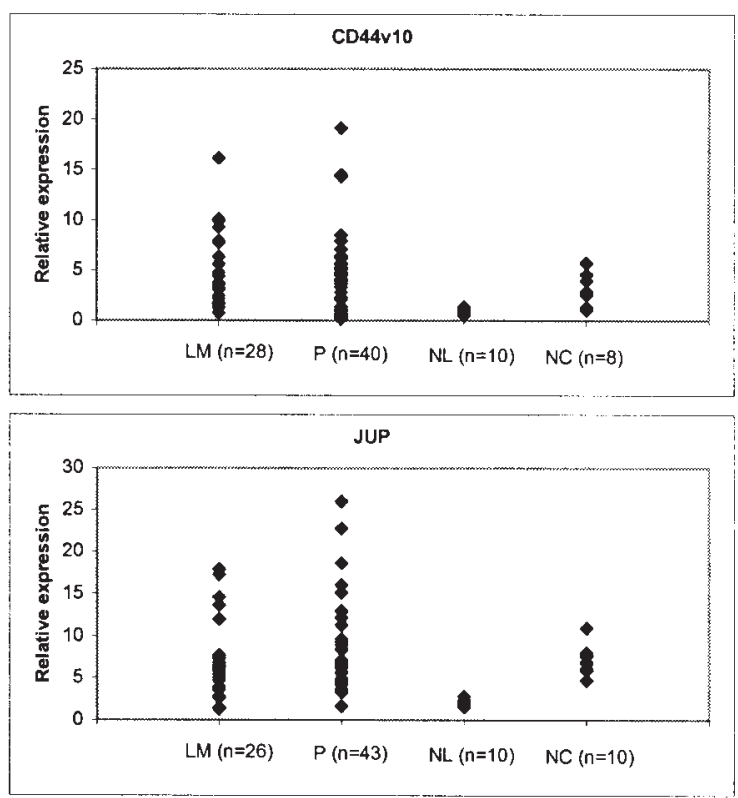

Figure 2. Scatterplots of QPCR-measured gene expression. (B) Expression of genes that failed the validation. Expression (y-axis) is relative to reference RNA. LM, liver metastases; P, primary tumours; NL, normal liver; NC, normal colon; n, number of samples analyzed for each tissue group.
B-cell membrane protein CD22. The presence of genes expressed by immune cells is consistent with immune cell infiltration observed microscopically in tissue sections of metastases. Genes expressed by both immune cells and tumour cells, such as the chemokine receptor CXCR4 and its ligand CXCL12 (11), were also present in this gene subset.

Genes associated with tissue remodelling mainly encode extracellular matrix proteins, matricellular proteins, integrins, proteases and cell adhesion molecules. Examples of such genes are collagen type 1, fibronectin, osteopontin, ADAM17, versican and decorin.

Genes associated with proliferation and oxidative phosphorylation are downregulated in liver metastases. Several statistically significant biological functions were found among genes downregulated in liver metastases relative to primary tumours (Table II). Two biological functions that could relate to the effect of the liver on the metastases are cell proliferation and oxidative phosphorylation. Genes associated with cell proliferation mainly encode proteins involved in cell cycle processes such as CDC2, CKS2, MCM2, MCM6 and MKI67. Genes associated with oxidative phosphorylation encode proteins for the mitochondrial electron transport chain, which are subunits of Complex I, Complex III, Complex IV and Complex V.
Validation by quantitative real-time PCR ( $Q P C R)$. The mRNA expression of selected genes were analysed by QPCR to confirm differential expression between liver metastases and primary tumours. Eight out of 13 genes were differentially expressed (Table III and Fig. 2).

CXCL12, CXCR4, osteopontin, ADAM17 and versican were confirmed to have higher expression in metastases than primary tumours. The expression levels of these five genes were also higher in metastases than normal liver, except for CXCL12 (Fig. 2A). CKS2, LCN2 and PRDX1 were also confirmed to be downregulated in metastases relative to primary tumours (Table III). The expression level of these 3 genes were the highest in primary tumours among all the tissues analysed (Fig. 2A).

RET, CD44v10, HMGA1, JUP and TLL2 were not significantly differentially expressed according to QPCR (Table III and Fig. 2B), highlighting the importance of validating microarray data $(12,13)$.

\section{Discussion}

The gene expression of colorectal primary tumours and liver metastases were profiled on microarrays. Unsupervised hierarchical clustering of these expression profiles could classify the tumours into their respective groups, demonstrating that liver metastases have a different gene expression profile from primary tumours. SAM analysis between primary 
Table III. Results of QPCR validation of selected genes.

\begin{tabular}{|c|c|c|c|c|c|c|c|}
\hline \multirow[b]{2}{*}{$\begin{array}{l}\text { Gene } \\
\text { symbol }\end{array}$} & \multirow[b]{2}{*}{ Gene name } & \multirow[b]{2}{*}{$\begin{array}{l}\text { Entrez } \\
\text { Gene } \\
\text { ID }\end{array}$} & \multirow[b]{2}{*}{$\begin{array}{c}\text { Number } \\
\text { of samples } \\
(\mathrm{LM} / \mathrm{P})\end{array}$} & \multirow[b]{2}{*}{$\begin{array}{l}\text { Microarray } \\
\text { fold } \\
\text { change } \\
(\mathrm{LM} / \mathrm{P})\end{array}$} & \multicolumn{3}{|c|}{ QPCR validation } \\
\hline & & & & & $\begin{array}{l}\text { QPCR } \\
\text { fold } \\
\text { change } \\
(\mathrm{LM} / \mathrm{P})\end{array}$ & $\begin{array}{c}\text { P-value of } \\
\text { LM vs. P } \\
\text { (one-tail T-test, } \\
\alpha=0.01 \text { ) }\end{array}$ & $\begin{array}{l}\text { Significant } \\
\text { difference }\end{array}$ \\
\hline CSPG2 & $\begin{array}{l}\text { Versican (chondroitin sulphate } \\
\text { proteoglycan 2) }\end{array}$ & 1462 & $28 / 44$ & 2.6 & 8.6 & $2.4 \times 10^{-10}$ & Yes \\
\hline CXCR4 & $\begin{array}{l}\text { Chemokine (C-X-C motif) } \\
\text { receptor } 4\end{array}$ & 7852 & $28 / 40$ & 1.9 & 5.3 & $1.6 \times 10^{-8}$ & \\
\hline ADAM17 & $\begin{array}{l}\text { A disintegrin and } \\
\text { metalloproteinase domain } 17\end{array}$ & 6868 & $26 / 39$ & 1.8 & 1.7 & $8.6 \times 10^{-5}$ & \\
\hline PRDX1 & Peroxiredoxin 1 & 5052 & $28 / 40$ & $1 / 1.8$ & $1 / 2.3$ & 0.00014 & \\
\hline SPP1 & $\begin{array}{l}\text { Osteopontin (secreted } \\
\text { phosphoprotein } 1)\end{array}$ & 6696 & $28 / 44$ & 5.8 & 9.7 & 0.00042 & \\
\hline CXCL12 & $\begin{array}{l}\text { Chemokine (C-X-C motif) } \\
\text { ligand } 12\end{array}$ & 6387 & $25 / 44$ & 1.6 & 2.8 & 0.00056 & \\
\hline $\mathrm{CKS} 2$ & $\begin{array}{l}\text { CDC28 protein kinase } \\
\text { regulatory subunit } 2\end{array}$ & 1164 & $28 / 40$ & $1 / 2.2$ & $1 / 2.3$ & 0.0012 & \\
\hline LCN2 & Lipocalin 2 (oncogene 24p3) & 3934 & $28 / 40$ & $1 / 5$ & $1 / 25$ & 0.0014 & \\
\hline TLL2 & Tolloid-like 2 & 7093 & $25 / 37$ & 5.5 & $1 / 1.9$ & - & No \\
\hline CD44v10 & $\begin{array}{l}\text { Soluble CD44 with exon v10 } \\
\text { extension }\end{array}$ & 960 & $28 / 40$ & 2.0 & 1.1 & 0.31 & \\
\hline HMGA1 & High mobility group AT-hook 1 & 3159 & $28 / 38$ & $1 / 1.6$ & $1 / 1.4$ & 0.018 & \\
\hline JUP & Junction plakoglobin & 3728 & $26 / 43$ & $1 / 2.0$ & $1 / 1.2$ & 0.13 & \\
\hline RET & Ret proto-oncogene & 5979 & $28 / 43$ & 2.6 & 1.3 & 0.3 & \\
\hline
\end{tabular}

tumours and metastases identified a list of differentially expressed genes but none of the 778 differentially expressed annotated genes were in common with the six genes reported by D'Arrigo et al and the 40 genes reported by Yanagawa et al $(7,8)$. Despite the lack of concordance with these two microarray studies, our list of differentially expressed genes comprised genes that agree with studies using non-microarray methods to investigate gene expression in tumours (cited throughout discussion).

The lack of concordance with microarray studies is likely due to differences in array clone sets or tissue specificity. Arrays used by D'Arrigo et al and Yanagawa et al were cDNA arrays of 7,864 and 9,121 genes, respectively $(7,8)$. Both studies analysed matched tumour pairs which were subjected to laser-capture microdissection of tumour cells. The tumour samples in our investigation were processed whole to take account of the biology of the tumour stroma because many studies have shown that tumour growth is influenced by the tumour stroma (14-16).
Tumour stroma not only consists of extracellular matrix, but also comprises vascular cells, immune cells and fibroblasts. These cells can secrete cytokines, growth factors and enzymes that can promote tumour progression. Studies of cancer-associated fibroblasts promoting malignant-transformation and tumour growth were reviewed by Bhowmick et al (15) and Mueller and Fusenig (16). Gene expression changes between tumour stroma of metastases and primary tumours which may contribute to tumour progression can thus be observed by processing the tumour samples whole.

We found that genes associated with tissue remodelling and immune response were upregulated in liver metastases relative to primary tumours. Tissue remodelling and immune response are processes associated with wound-healing. Tumours are referred to as 'wounds that do not heal' because extracellular matrix changes and inflammatory processes similar to that of wound healing are observed in the tumour site (17). The genes associated with tissue remodelling and immune response may 
be expressed by either tumour stromal cells or tumour cells. Expression of these genes by stromal cells would indicate that the tumour stroma of metastases is different from the primary tumour and may be enabling the growth of colorectal tumour cells in a different environment. Regardless of the source of expression, the proteins encoded by these genes can influence tumour invasion and growth.

Genes associated with tissue remodelling found to be upregulated in liver metastases relative to primary tumours include those that encode collagens, fibronectin and proteoglycans, which are commonly found in tumour stroma (18-20). Such extracellular matrix molecules are not only important for structural support, but can also promote angiogenesis, growth and invasion, as illustrated by versican in cell line studies $(21,22)$. Increased versican expression was reported in colorectal primary tumours relative to normal colon (23), and our QPCR analysis showed that versican was upregulated in liver metastases relative to primary tumours, indicating that increasing levels of versican may be associated with colorectal cancer progression.

Two other tissue remodelling genes confirmed by QPCR analysis to be upregulated in liver metastases relative to primary tumours are osteopontin and ADAM17. Osteopontin, a matricellular protein important in tissue repair was shown to enhance the motility and invasiveness of colorectal cancer cells (24). Osteopontin is likely to be important in colorectal cancer progression, as its expression in colorectal cancer was shown to increase with tumour progression (25). Furthermore, in vivo studies showed that osteopontin silencing reduced colorectal metastases growth in mice (26).

ADAM17 is a transmembrane protease that may be involved in modulating extracellular matrix turnover in tumour stroma as it can cleave proteoglycans such as versican (27) and collagen IV (28). This enzyme has been reported to be upregulated in colorectal primary tumours relative to normal colon (29). Another potential role of ADAM17 in the metastatic process is to promote inflammation since the proteolytic action of the enzyme can also release membranebound cytokines such as tumour necrosis factor- $\alpha$ (28).

The increased expression of genes associated with tissue remodelling in metastases relative to primary tumours may be a mechanism that enables colorectal tumour cells to invade and colonise the liver, since these genes encode molecules that can influence invasion and growth. By remodelling the surrounding tissue, the metastatic colorectal cells may be creating a suitable microenvironment to support growth in a foreign organ.

As previously mentioned, the inflammatory processes observed in tumours are similar to that of wound-healing. Inflammation is linked to the development of cancer, and the paradoxical role of immune cells on cancer progression was recently discussed by de Visser et al (30). One of the functions of immune cells is to eliminate damaged cells but studies are demonstrating that immune cells can promote tumour progression through inflammatory processes (30). We found that genes expressed by the innate and adaptive immune cells were upregulated in metastases relative to primary tumours, indicating the presence of chronic inflammation in metastases. Inflammation is likely to be induced by the host liver as a defence response against the foreign invading tumour cells, but inflammation can also stimulate tumour growth. Chronic activation of innate immune cells can modulate cell survival, angiogenesis and tissue remodelling through the production of growth factors, cytokines and metalloproteinases (30). Studies in mouse models have shown that the attenuation of innate immune cell infiltration reduces tumour development (30).

Certain genes expressed by immune cells may also be expressed by tumour cells, as illustrated by the chemokine receptor CXCR4 and its ligand CXCL12 (11). The proteins encoded by both of these genes are involved in the trafficking of immune cells to injured tissue, and their expression was observed in various cancers including colorectal cancer $(11,31)$. Our QPCR analysis confirmed the upregulation of both genes in metastases relative to primary tumours. Since CXCL12CXCR4 signalling can induce cell migration, these proteins may be involved in invasion of colorectal tumour cells in liver. Additionally, CXCL12 can induce angiogenesis by regulating endothelial cell trafficking and responses (32). In vivo studies using xenograft techniques on mice showed that CXCL12 from carcinoma-associated stromal fibroblasts of breast tumours promoted angiogenesis in breast tumours (33). High CXCR4 expression in colorectal cancer was reported to correlate with poor prognosis and metastasis (34). In vivo studies on mice demonstrated that CXCR4 was required for the growth of colorectal metastases in distant organs, as micrometastases formed by CXCR4-deficient tumour cells did not expand (35).

We found that genes associated with proliferation were downregulated in liver metastases relative to primary tumours. These genes mainly encode proteins involved in cell cycle processes such as CDC2, CKS2, MCM2, MCM6 and Ki67, and thus are indicators of cell proliferation. Downregulation of such genes indicate that colorectal tumour cells were not proliferating in the liver as rapidly as in the colon, which was an unexpected finding since tumour progression is usually associated with increased proliferation of tumour cells. Decreased proliferation of liver metastases relative to colorectal primary tumours has been reported by other studies using Ki67 or PCNA immunostaining to assess proliferation $(36,37)$. We also found that genes encoding the mitochondrial electron transport chain were downregulated in metastases relative to primary tumours, which would be consistent with decreased energy requirements of reduced proliferation.

Our QPCR confirmed that the expression of two genes associated with proliferation, CKS2 and PRDX1, were upregulated in primary tumour samples relative to normal colon, but were downregulated in metastases relative to primary tumours, indicating decreased proliferation of metastatic cells. CKS2 protein is essential for the function of cyclin dependent kinases. PRDX1 protein is an antioxidant enzyme with proliferative properties where fibroblasts lacking PRDX1 showed decreased proliferation (38).

The reduced expression of genes associated with proliferation in metastases suggests that the proliferative activity of tumour cells may be affected by the liver microenvironment which may be lacking appropriate growth signals. It is unlikely that the downregulation of these genes were caused by the anti-proliferative effect of the systemic chemo- 
therapy drugs fluorouracil and leucovorin which were given to $70 \%$ of the patients prior to liver resection. SAM comparison between the gene expression profile of metastases from chemotherapy-treated patients and nontreated patients did not identify any differentially expressed genes, thus ruling out the possiblity of chemotherapy influencing the proliferation of metastases.

In summary, our study shows that liver metastases undergo gene expression changes that distinguishes them from primary tumours. These gene expression changes are likely to be important for the invasion and colonisation of metastases in the new organ site, as illustrated by the upregulation of genes associated with tissue remodelling and immune response which can enhance tumour progression. We also found that genes associated with proliferation were downregulated in metastases relative to primary tumours, which may be caused by the liver microenvironment. The decreased proliferative activity in metastases relative to primary tumours is currently being investigated.

\section{Acknowledgements}

We would like to express our gratitude to Pacific Edge Biotechnology Limited for supplying the microarray slides and reference RNA, and to Franz Pichler (University of Auckland, New Zealand) for providing the normalisation method. This research was funded by the Health Research Council, the National Research Centre for Growth and Development, and the Cancer Society of New Zealand.

\section{References}

1. Adam R and Vinet E: Regional treatment of metastasis: Surgery of colorectal liver metastases. Ann Oncol 15 (Suppl 4): 103-106, 2004.

2. Shih W, Chetty R and Tsao MS: Expression profiling by microarrays in colorectal cancer (Review). Oncol Rep 13: 517-524, 2005.

3. Friederichs J, Rosenberg R, Mages J, Janssen KP, Maeckl C, Nekarda H, Holzmann B and Siewert JR: Gene expression profiles of different clinical stages of colorectal carcinoma: Toward a molecular genetic understanding of tumor progression. Int J Colorectal Dis 20: 391-402, 2005.

4. Bertucci F, Salas S, Eysteries S, Nasser V, Finetti P, Ginestier C, Charafe-Jauffret E, Loriod B, Bachelart L, Montfort J, Victorero G, Viret F, Ollendorff V, Fert V, Giovaninni M, Delpero JR, Nguyen C, Viens P, Monges G, Birnbaum D and Houlgatte R: Gene expression profiling of colon cancer by DNA microarrays and correlation with histoclinical parameters. Oncogene 23: 1377-1391, 2004.

5. Li MH, Lin YM, Hasegawa S, Shimokawa T, Murata K, Kameyama M, Ishikawa O, Katagiri T, Tsunoda T, Nakamura Y and Furukawa Y: Genes associated with liver metastasis of colon cancer, identified by genome-wide cDNA microarray. Int J Oncol 24: 305-312, 2004.

6. Williams NS, Gaynor RB, Scoggin S, Verma U, Gokaslan T, Simmang C, Fleming J, Tavana D, Frenkel E and Becerra C: Identification and validation of genes involved in the pathogenesis of colorectal cancer using cDNA microarrays and RNA interference. Clin Cancer Res 9: 931-946, 2003.

7. Yanagawa R, Furukawa Y, Tsunoda T, Kitahara O, Kameyama M, Murata K, Ishikawa O and Nakamura Y: Genome-wide screening of genes showing altered expression in liver metastases of human colorectal cancers by cDNA microarray. Neoplasia 3 : 395-401, 2001

8. D'Arrigo A, Belluco C, Ambrosi A, Digito M, Esposito G, Bertola A, Fabris M, Nofrate V, Mammano E, Leon A, Nitti D and Lise M: Metastatic transcriptional pattern revealed by gene expression profiling in primary colorectal carcinoma. Int $\mathbf{J}$ Cancer 115: 256-262, 2005.
9. Colantuoni C, Henry G, Zeger S and Pevsner J: SNOMAD (standardization and normalization of microarray data): Webaccessible gene expression data analysis. Bioinformatics 18: 1540-1541, 2002.

10. Livak KJ and Schmittgen TD: Analysis of relative gene expression data using real-time quantitative PCR and the 2(-delta delta $\mathrm{c}(\mathrm{t})$ ) method. Methods 25: 402-408, 2001.

11. Balkwill F: The significance of cancer cell expression of the chemokine receptor CXCR4. Semin Cancer Biol 14: 171-179, 2004.

12. Chuaqui RF, Bonner RF, Best CJ, Gillespie JW, Flaig MJ, Hewitt SM, Phillips JL, Krizman DB, Tangrea MA, Ahram M, Linehan WM, Knezevic V and Emmert-Buck MR: Post-analysis follow-up and validation of microarray experiments. Nat Genet 32 (Suppl): 509-514, 2002.

13. Kothapalli R, Yoder SJ, Mane S and Loughran TP Jr: Microarray results: How accurate are they? BMC Bioinformatics 3: 22, 2002.

14. Liotta LA and Kohn EC: The microenvironment of the tumourhost interface. Nature 411: 375-379, 2001

15. Bhowmick NA, Neilson EG and Moses HL: Stromal fibroblasts in cancer initiation and progression. Nature 432: 332-337, 2004.

16. Mueller MM and Fusenig NE: Friends or foes - bipolar effects of the tumour stroma in cancer. Nat Rev Cancer 4: 839-849, 2004.

17. Brower V: Feeding the flame: New research adds to role of inflammation in cancer development. J Natl Cancer Inst 97: 251-253, 2005.

18. Kinsella MG, Bressler SL and Wight TN: The regulated synthesis of versican, decorin, and biglycan: Extracellular matrix proteoglycans that influence cellular phenotype. Crit Rev Eukaryot Gene Expr 14: 203-234, 2004.

19. Gulubova MV: Collagen type iv, laminin, alpha-smooth muscle actin (alphasma), alpha1 and alpha6 integrins expression in the liver with metastases from malignant gastrointestinal tumours. Clin Exp Metastasis 21: 485-494, 2004.

20. Kalluri R: Basement membranes: Structure, assembly and role in tumour angiogenesis. Nat Rev Cancer 3: 422-433, 2003.

21. Zheng PS, Wen J, Ang LC, Sheng W, Viloria-Petit A, Wang Y, Wu Y, Kerbel RS and Yang BB: Versican/PG-M G3 domain promotes tumor growth and angiogenesis. FASEB J 18: 754-756, 2004.

22. Cattaruzza S, Schiappacassi M, Kimata K, Colombatti A and Perris R: The globular domains of PG-M/versican modulate the proliferation-apoptosis equilibrium and invasive capabilities of tumor cells. FASEB J 18: 779-781, 2004.

23. Theocharis AD: Human colon adenocarcinoma is associated with specific post-translational modifications of versican and decorin. Biochim Biophys Acta 1588: 165-172, 2002.

24. Irby RB, McCarthy SM and Yeatman TJ: Osteopontin regulates multiple functions contributing to human colon cancer development and progression. Clin Exp Metastasis 21: 515-523, 2004.

25. Coppola D, Szabo M, Boulware D, Muraca P, Alsarraj M, Chambers AF and Yeatman TJ: Correlation of osteopontin protein expression and pathological stage across a wide variety of tumor histologies. Clin Cancer Res 10: 184-190, 2004.

26. Wai PY, Mi Z, Guo H, Sarraf-Yazdi S, Gao C, Wei J, Marroquin CE, Clary B and Kuo PC: Osteopontin silencing by small interfering RNA suppresses in vitro and in vivo ct26 murine colon adenocarinoma metastasis. Carcinogenesis 26: 741-751, 2005.

27. Sandy JD, Westling J, Kenagy RD, Iruela-Arispe ML, Verscharen C, Rodriguez-Mazaneque JC, Zimmermann DR, Lemire JM, Fischer JW, Wight TN and Clowes AW: Versican v1 proteolysis in human aorta in vivo occurs at the Glu441-Ala442 bond, a site that is cleaved by recombinant ADAMTS- 1 and ADAMTS-4. J Biol Chem 276: 13372-13378, 2001.

28. Bauvois B: Transmembrane proteases in cell growth and invasion: New contributors to angiogenesis? Oncogene 23: 317-329, 2004.

29. Blanchot-Jossic F, Jarry A, Masson D, Bach-Ngohou K, Paineau J, Denis MG, Laboisse CL and Mosnier JF: Up-regulated expression of ADAM17 in human colon carcinoma: Coexpression with EGFR in neoplastic and endothelial cells. J Pathol 207: 156-163,2005.

30. de Visser KE, Eichten A and Coussens LM: Paradoxical roles of the immune system during cancer development. Nat Rev Cancer 6: 24-37, 2006. 
31. Brand S, Dambacher J, Beigel F, Olszak T, Diebold J, Otte JM, Goke B and Eichhorst ST: CXCR4 and CXCL12 are inversely expressed in colorectal cancer cells and modulate cancer cell migration, invasion and MMP-9 activation. Exp Cell Res 310: 117-130, 2005.

32. Salcedo R and Oppenheim JJ: Role of chemokines in angiogenesis: CXCL12/sdf-1 and CXCR4 interaction, a key regulator of endothelial cell responses. Microcirculation 10: 359-370, 2003.

33. Orimo A, Gupta PB, Sgroi DC, Arenzana-Seisdedos F, Delaunay T, Naeem R, Carey VJ, Richardson AL and Weinberg RA: Stromal fibroblasts present in invasive human breast carcinomas promote tumor growth and angiogenesis through elevated SDF-1/CXCL12 secretion. Cell 121: 335-348, 2005.

34. Kim J, Takeuchi H, Lam ST, Turner RR, Wang HJ, Kuo C, Foshag L, Bilchik AJ and Hoon DS: Chemokine receptor CXCR4 expression in colorectal cancer patients increases the risk for recurrence and for poor survival. J Clin Oncol 23: 2744-2753, 2005.
35. Zeelenberg IS, Ruuls-Van Stalle L and Roos E: The chemokine receptor CXCR4 is required for outgrowth of colon carcinoma micrometastases. Cancer Res 63: 3833-3839, 2003.

36. Seong J, Cho JH, Yang WI, Chung EJ and Kim NK: Apoptosis and proliferation in paired primary colorectal adenocarcinomas and their liver metastases. Yonsei Med J 45: 187-192, 2004.

37. Agui T, McConkey DJ and Tanigawa N: Comparative study of various biological parameters, including expression of survivin, between primary and metastatic human colonic adenocarcinomas. Anticancer Res 22: 1769-1776, 2002.

38. Neumann CA, Krause DS, Carman CV, Das S, Dubey DP, Abraham JL, Bronson RT, Fujiwara Y, Orkin SH and Van Etten RA: Essential role for the peroxiredoxin PRDX1 in erythrocyte antioxidant defence and tumour suppression. Nature 424: 561-565, 2003. 